\title{
مصطلح mk (الحماية) في اللغة المصرية القديمة
}

أ.د/ صدقه موسي علي

أ/هاجر بهي الاين خفاجي محمي علدي

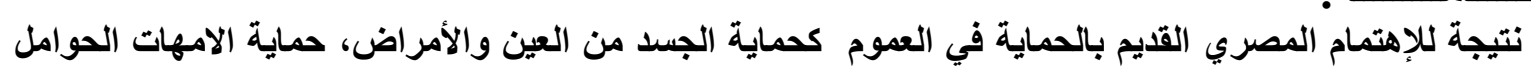

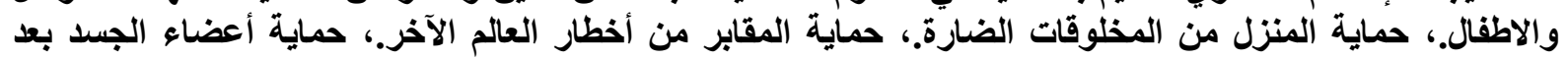
فنتيجة لكل تلك الإهتمامات فقد أمدتنا اللغة المصرية القديمة وبعض الثواهد الكتابية بالعديد من المصطلحات اللغوية

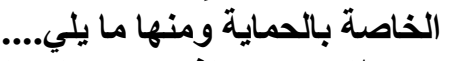
مصطلح Mk الأي وجد لله العديا من الألفاظ منها: : يعني حماية وتقادٍ ،وله عدة اشكال منها : Mki(')

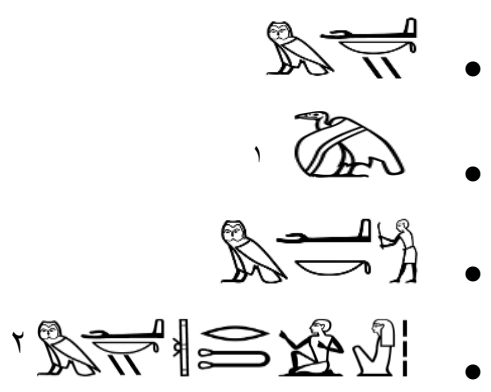

ولقد وجد عدة أمثلة ذُكر فيها لفظ mki مثل:

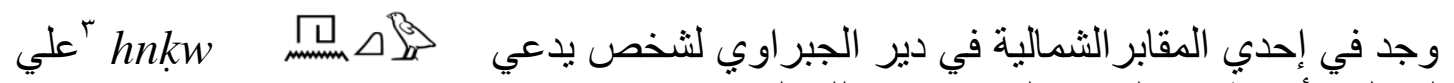
السجل الأوسطٌ من الجدار الشرقي من تلك المقبرة نقش كبير هو:

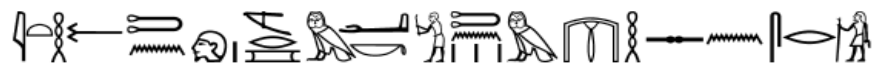

I th th tp $m r$ mki tn $m$ (zh) $n$ isr

انك المحبوب المحمي في قاعة المسئولين؛

Mkit (Y)

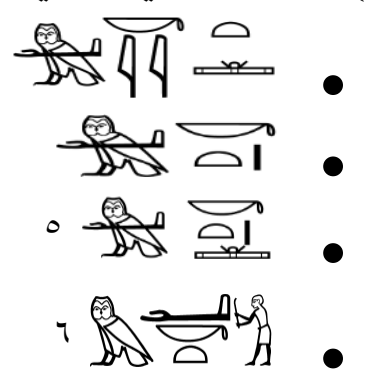

ولقد وجد عدة أمثلة ذُكر فيها لفظ mkit مثل: وجد في نصوص الاهر ام الخاصة بهرم الملك اوناس في سقارة :

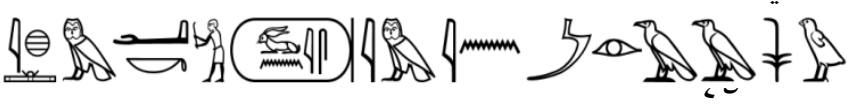


ih mki.t (wnis)/ im in m33.w sw يا اوناس انت محمي من قبل الذين يرونك.

: Mkti (r)

की

$\wedge$
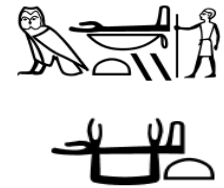

(2)

ومن مشتقات مصطلح mk في اللغة المصرية القديمة:

ـ - - (اي) (mki sw) : (ايحمي نفسه ،ومن اشكاله:

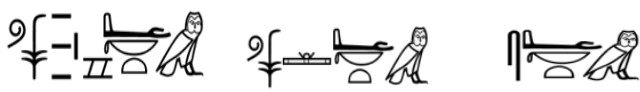

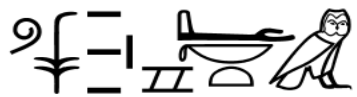

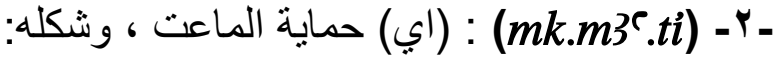

ํำด

-

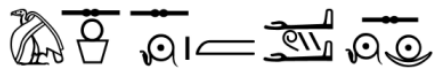

ـ - - (mk-ib-n-nb-r-dr): (اي) الذي يحمي قلب سيد الجميع ، وشكله: ond

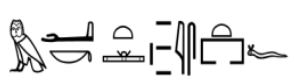

ـ- - (mkty-is.f): (اي) حامي قبره ، وشكله: ‘' ـ

(mkt-hwwt) - - V(A) Dلم 
${ }^{1}$ Budge,w., Egyptian Heroglyphic Dictionary, Vol I, London ,1920, p.288.

${ }^{2}$ Wb.II, 162,1-2.

${ }^{3} \mathrm{PN}, \mathrm{I}, 230.4$.

${ }^{4}$ Kanawati, N., Deir el-Gebrawi I The northern cliff, 2005,Oxford , pp.71-73, pl.29-30,56,66-

67;Urk.I, 76-79

${ }^{5}$ Budge,w., Heroglyphic Dictionary,p.288.

${ }^{6} \mathrm{~Wb}, \mathrm{II}, 162: 3$.

${ }^{7}$ Sethe, K., Pyr.texte, Bd. I, Leipzig 1908,PT 254(278a) ; Piankoff, A., The Pyramid of Unas, Texts Translated with Commentary, ERTR 5, Princeton 1968, pl. 14-17 [P,Ü,K].

${ }^{8} \mathrm{~Wb}$ II, 161,6-7.

${ }^{9}$ Budge,W., Heroglyphic Dictionary,p.288.

${ }^{10}$ LGG.III,451,448 .

${ }^{11}$ Wb. II,161-1.

${ }^{12}$ LGG,III,455 